The children are our future

There can be few things more important than the way we educate our children, and in the United States this has led to a longstanding battle over the prominence and emphasis given to the teaching of evolution in schools. Continued debate about the importance of teaching a subject that has such an established and overwhelming evidence base is perhaps indicative of the treatment that the science of climate change could receive. Indeed, the teaching of climate science has become a political issue in many schools across the United States. In a News Feature, Mason Inman takes a look at the battle for the minds and hearts of US school children. [News Feature p303]

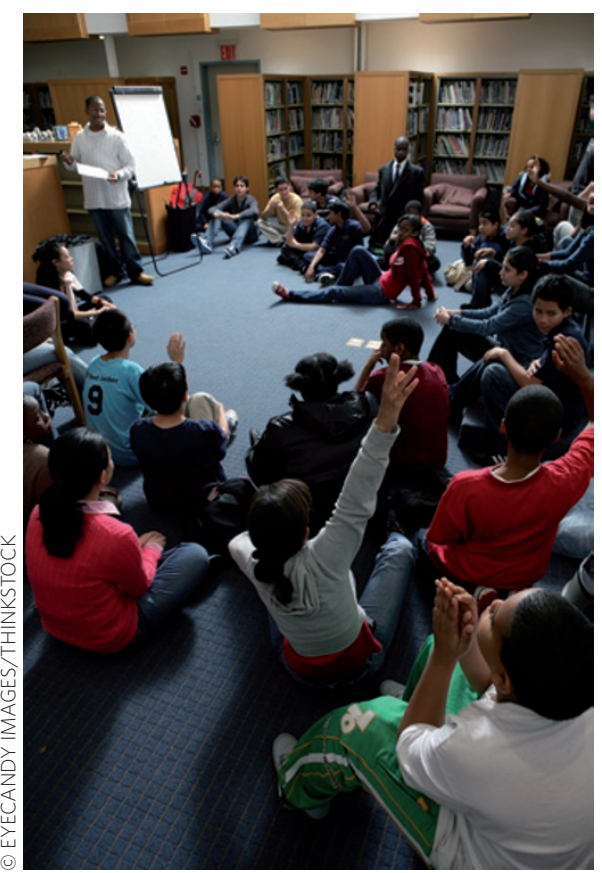

\section{Assessing bioenergy}

The Intergovernmental Panel on Climate Change's Special Report on Renewable Energy Sources and Climate Change Mitigation (SRREN) assessed the role of bioenergy as a solution to meeting greenenergy demand. Based on integrated assessment models, the SRREN states that deployed bioenergy will contribute the greatest proportion of primary energy among renewable energies and result in greenhouse-gas emission reductions. However, the report also acknowledges insights from life-cycle assessments, which characterize biofuels as a potential source of significant greenhouse-gas emissions and environmental harm. The report therefore encompassed information from both disciplines, but failed to reconcile their contrasting insights. A Perspective discusses the merits of each approach and advocates an integrated research agenda.

\section{[Perspective p320]}

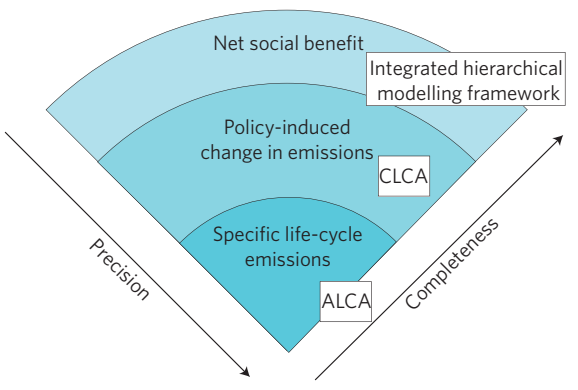

\section{Polar freshwater impacts}

Among the fastest rates of recent climate warming have been reported for the Arctic and maritime Antarctic. A study now investigates the effects of warming on polar freshwater systems where cyanobacterial mats represent the dominant benthic primary producers. Exposing polar mat samples to raised temperatures for six months resulted in a change in species predominance and toxin production. The study provides experimental evidence that increased temperatures could affect cyanobacterial mat species diversity, with the potential to profoundly alter freshwater polar ecosystems.

[Letter p356]

\section{Carbon intelligence for sale}

An army of consultants and advisors has sprung up to provide information to help organizations sell or purchase carbonbased credits for local national and regional legal compliance, and understand their own carbon footprint. The provision of these services collectively categorized as carbon-market intelligence has led to the emergence of a new sector that is estimated to be worth over $£ 35$ billion (based on 2010-2011 figures). In a Commentary, Mark Maslin and Martyn Poessinouw discuss the emergence and rapid growth of this new carbon sector.

[Commentary p300]

\section{Carbon-intensity ambitions}

The Chinese economy has been growing at a phenomenal rate over the past decade and even conservative estimates for the future indicate a steep continuation of this trend, with six of China's 22 provinces expected to have economies worth US $\$ 1$ trillion by 2020 (that is, at least as big as Mexico's economy at present). 2020 is also the self-imposed deadline by which China intends to cut its carbon-emissions intensity - the carbon dioxide emitted per dollar of gross domestic product - by $40-45 \%$ relative to 2005 levels. Whether China will be able to meet this target, while experiencing such high growth, remains to be seen. Anna Petherick investigates a number of experimental carbontrading schemes that may offer part of the solution. [Market Watch p309]

\section{Glacial biodiversity}

In many regions climate change is reducing the glacial meltwater contribution to river flow, but the effect of these changes on specialized glacier-fed river communities is poorly quantified. Now research demonstrates that $11-38 \%$ of the regional species pools can be expected to be lost following complete disappearance of glaciers in a catchment. Even more-steady shrinkage is likely to reduce taxon turnover in proglacial river systems and local richness at downstream reaches where glacial cover in the catchment is less than $5-30 \%$. These findings point to the vulnerability of local biodiversity hotspots and indicate that the number of species lost is likely to be much higher than the few specialist species found only in glacier-fed rivers.

[Letter p361; News \& Views p318]

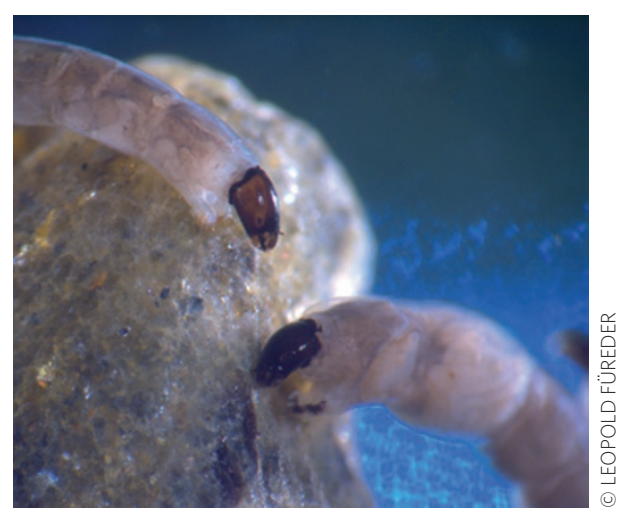

\section{European aircraft emissions}

Aviation emissions have more than doubled in the past 20 years and this level of growth is expected to continue until at least 2050. Tackling greenhouse-gas emissions from aircraft is a difficult task, but Europe laid down the groundwork for one potential solution when it passed legislation to include international flights in its carbontrading scheme in 2009. Sonja van Renssen investigates the prospects for Europe's approach to this problem. [Policy Watch p308] 